\title{
On the Short-Term Optimisation of a Hydro Basin with Social Constraints
}

\author{
Gloria Hermida, Edgardo D. Castronuovo \\ University Carlos III de Madrid, Madrid, Spain \\ Email: gloriahermida@gmail.com, ecastron@ing.uc3m.es
}

Received November 19, 2012; revised December 20, 2012; accepted January 3, 2013

\begin{abstract}
In this paper, an optimisation problem for calculating the best energy bids of a set of hydro power plants in a basin is proposed. The model is applied to a real Spanish basin for the short-term (24-hour) planning of the operation. The algorithm considers the ecological flows and social consumptions required for the actual operation. One of the hydro plants is fluent, without direct-control abilities. The results show that the fluent plant can be adequately controlled by using the storage capacities of the other plants. In the simulations, the costs related to the social consumptions are more significant than those due to the ecological requirements. An estimate of the cost of providing water for social uses is performed in the study.
\end{abstract}

Keywords: Hydro Power Plants; Hydro Generation; Optimisation; Short-Term Planning; Social Resources

\section{Introduction}

Nowadays, the utilisation of water for electricity production is conditioned by many constraints. In Spain, primarily the Kyoto Agreements and the proposals of the European Commission to 2020 must be considered. The European Commission have specified a goal of $20 \%$ of the final energy consumption delivered from renewable sources by 2020 [1]. In Spain, $38.6 \%$ of the electricity generation comes from renewable resources, mainly from hydro (17.4\%) and wind (16.6\%) generation [2]. Because electricity generation has to compensate for other nonrenewable energy consumptions, electricity production must increase its share of renewable generation. Hydro production is a mature renewable technology that can help reach the ambitious objectives proposed by the European Commission by 2020.

In addition, the exceptionally variable weather conditions of the past few years, most likely due to climate change, complicate the management of water for electricity production. The scarcity and the high variability of water resources have recently reduced the profits in several zones [3-6].

Many studies have been performed to calculate the optimal operation of a hydro basin. In long-term planning, Soares and Carneiro [7] consider the operation planning of a hydrothermal power system in Brazil. The paper highlights the importance on the control of the head hydro power plants (HPPs) in the basin. Granville et al. [8] consider the stochastic characteristics of the problem, including a representation of the market. The solution algorithm is based on stochastic dual dynamic programming. Cheng [9] applies particle swarm optimisation and dynamic programming for a large scale hydro system in China. Oliveira, Binato and Pereira [10] present two techniques: the extension of a binary disjunctive technique and screening strategies for planning studies in Brazil and Bolivia. Fosso et al. [11] give an overview of the planning tool used in Norway for long, medium and short horizons. Kanudia and Loulou [12] propose a stochastic version of the extended market allocation model for a hydro system in Québec, Canada.

In medium- and short-term planning, Habibollahzadeh and Bubenko [13] compare different mathematical methods: Heuristic, Benders and Lagrange methods for hydroelectric generation scheduling in the Swiss system. Castronuovo and Peças Lopez [14] describe economic profits of the coordination of wind and hydro energies. Zhao and Davison [15] analyse the inclusion of storage facilities in a hydro system, demonstrating the sensitive dependences between some of the parameters of the hydroelectric facility, the expected prices and water inflows. Pousinho, Mendes and Catalão [16] propose a mixedinteger quadratic programming approach for the shortterm hydro scheduling problem, considering discontinuous operating regions and discharge ramping constraints. Simopoulos, Kavatza and Vournas [17] propose a decoupling method, dividing the hydrothermal problem into hydro and thermal sub-problems, which are solved independently. A Greek system is analysed in the study. Di- 
niz and Piñeiro Maceira [18] use a four-dimensional piecewise linear model for the generation of a hydro plant as a function of storage, turbined and spilled outflows. Shawwash, Thomas and Denis Russell [19] discuss the optimisation model used in the British Columbia hydro system for hydrothermal coordination.

Most of the available reports about the optimal programming of hydro generation have been published in countries with abundant water (Norway [11], Brazil [10], Canada [15], USA [19]). In the algorithms reported by these studies, the restrictions on the social use of water and the ecological minimum flows are either minimally considered or not considered at all, aiming at improving the utilisation of the abundant resource in a strictly economical environment. In Spain, the focus of the present study, ecological flows and social uses of water must be considered for the optimal utilisation of the resource. Pérez-Díaz and Wilhelmi [20] want to assess the economic impact of environmental constraints in the operation of a short-term hydropower plant. For that purpose, a revenue-driven daily optimisation model based on mixedinteger linear programming is applied to calculate the optimal operation of a HPP in the northwest area of Spain. In a more recent paper, Pérez-Díaz et al. [21] propose adding a pumping capability to improve the economic feasibility of an HPP project, always fulfilling the environmental constraints imposed on the operation of the hydropower plant.

This paper presents an optimisation algorithm for calculating the optimal energy bids of a set of HPPs, including the economic objectives for energy generation and the regulations concerning the use of water in the region. The algorithm is applied to the upper Guadalquivir Basin, an area with scarce resources and variable flows, over a 24-hour horizon. Four HPPs are considered in the analysis. Three of them have storage capacity and the other one is run-of-the-river, without directly controllable alternatives. All of the plants are operated jointly with a unique owner or dispatcher (as in current practical operation). Actual data from real power plants and markets are considered in this study, including the travel times of the water (TTW) between the HPPs. The results show that the fluent plant can be controlled to achieve optimal operation by using the upstream HPPs. Moreover, an estimate of the costs of providing water for social uses (as a function of reductions in profits from selling the electricity produced in the market) is made in this study.

\section{Rules Applicable to the Hydro Generation}

\subsection{Regulations Concerning the Use of Water for Electricity Generation}

The Water Framework Directive [22] establishes a Euro- pean Community framework for water protection and management. The objectives of this regulation are the prevention and reduction of pollution, promotion of sustainable water use, environmental protection, improvement in aquatic ecosystems and floods and drought mitigation. This norm was adapted to Spanish regulations by [23]. In this directive, the priorities regarding the use of water are fixed. Electricity generation is third in the order of precedence, after the use of water by the population and irrigation requirements. Additionally, this norm specifies the requirement of a Hydrological Plan for each basin or hydrological zone. In [24], the hydro regulations for the Andalucia region (the area considered in this study) are specified. The Guadalquivir Hydrographic Confederation (http://www.chguadalquivir.es) is the organisation designed to control the Guadalquivir basin. This organisation's website features historical data regarding affluences and other hydro information. The minimum levels of flows (ecological flows) are also specified for several points of the river.

\subsection{The Daily Energy Market}

In Spain, the electricity market has been deregulated since 1997 (Electricity Industry Act [25]). Some renewable productions have special incentives for their production (Royal Decree 661/2007 [26]). However, large or pre-existing hydro plants must auction their production in the conventional market without renewable bonuses and, practically, without special market regulation. This is the situation faced by the plants addressed in the present study.

The Spanish energy market is organised into the following sub-markets: futures market, daily market and several intra-daily markets. More than $95 \%$ of energy transactions and more than $80 \%$ of the economic volume are traded in the daily market [27]. There are also other markets that can affect hydroelectric production, such as the reserve and restriction management. For clarity, in this work, only daily market participation will be considered.

In the daily market, producers and consumers make their offers, in terms of energy quantity and prices for each hour of the $\mathrm{D}+1$ day. The Market Operator oversees the buying and selling of bids using a simple cassation model $[28,29]$. The present paper presents a method to calculate the optimal bids for energy over a 24-hour horizon of the hydro plants in the basin, assuming that the expected prices in these hours are known.

\section{Mathematical Formulation}

\subsection{Flow Chart}

In Figure 1, the flow chart of the algorithm is presented. 


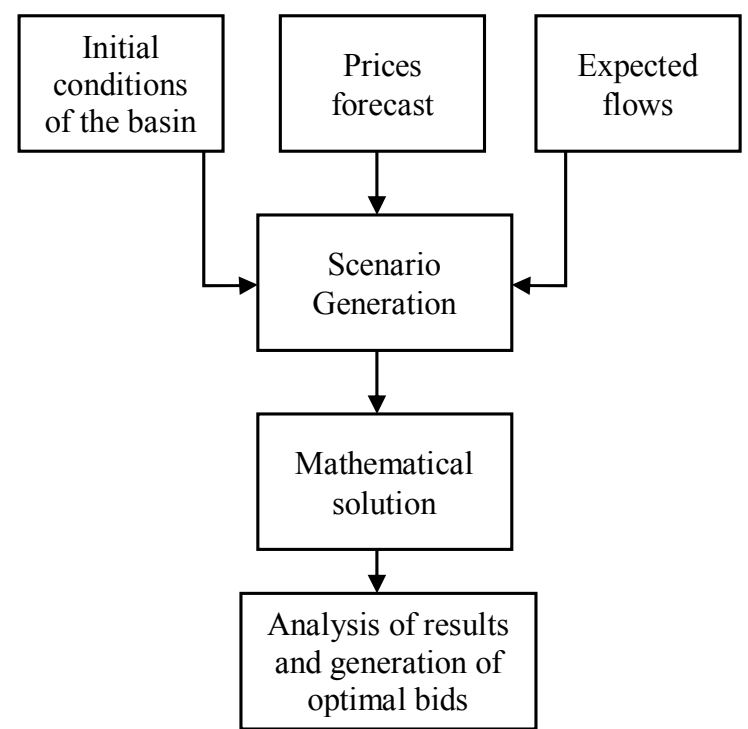

Figure 1. Flow chart of the proposed algorithm.

The initial conditions of the basin (level of stored water in the reservoirs, current flows, etc.) are known at the beginning of the study. Moreover, the expected flows in the analysed period can be considered known or estimated. The expected flows are depending also of the medium term planning for the operation of the basin. In the present study, an estimation of the prices in the market, for all the hours of the next day operation, is required. This prediction can be obtained from forecasting tools, outside the scope of the present study. With the knowledge of the initial condition, the price forecast and the expected flows, a scenario can be developed. In the present analysis, a determinist approach is used. However, the present method can be easily extended for considering uncertainties in the prices and/or in the expected flows, by solving many probable scenarios.

When the probable scenario is determined, the optimal solution for the operation in the hydro plants in the basin must be calculated. In the present case, ecological and social constraints are also included in the analysis. In the next section, a fully representation of the optimization problem is provided. After the calculation, the optimal flows of waters and the power and energy optimal bids are obtained. For achieving the profits presented in the analysis, it is considered that all the presented bids are accepted in the market, by offering the hydro production at low prices.

\subsection{Mathematical Representation}

The best operation of hydro plants in a basin can be calculated from the solution of an optimisation problem. In this problem, the restrictions to the operation are represented as mathematical constraints. The formulation of the problem is described by Equations (1)-(15).
Max.

$$
\sum_{i=1}^{n r+n w r} \sum_{t=1}^{T}\left(C_{t} \cdot P_{i, t}\right)
$$

s.t.

$$
\begin{gathered}
V_{i, t}=V_{i, t-1}+V_{i, t}^{A F}+V_{i-1, t}-V_{i, t}^{T}-V_{i, t}^{C}-V_{i, t}^{D} \\
i=1, \cdots, n r \\
V_{i, t}^{A F}+V_{i-1, t}-V_{i, t}^{T}-V_{i, t}^{C}-V_{i, t}^{D}=0 \\
i=1, \cdots, n w r \\
V_{i-1, t}=\sum_{\alpha i}\left(V_{i-1, t-t_{v}}^{T}+V_{i-1, t-t_{v}}^{D}\right) \\
i=1, \cdots,(n r+n w r) \\
V_{i, 1}=V_{i, 1}^{S P} \quad i=1, \cdots, n r \\
V_{i, T}=V_{i, T}^{S P} \quad i=1, \cdots, n r
\end{gathered}
$$

$$
P_{i, t}-\eta \cdot V_{i, t}^{T} \cdot g \cdot h_{i, t}=0 \quad i=1, \cdots,(n r+n w r)
$$

$h_{i, t}=k_{0, i}+k_{1, i} \cdot\left(V_{i}^{U}+V_{i}^{0}\right)$

$$
+k_{2, i} \cdot\left(V_{i}^{U}+V_{i}^{0}\right)^{2}+k_{3, i} \cdot\left(V_{i}^{U}+V_{i}^{0}\right)^{3}
$$

$$
i=1, \cdots,(n r+n w r)
$$

$$
\sum_{t=1}^{T} V_{i, t}^{C} \geq V_{i}^{C T \min } \quad i=1, \cdots,(n r+n w r)
$$

$$
V_{i}^{C \min } \leq V_{i, t}^{C} \leq V_{i}^{C \max } \quad i=1, \cdots,(n r+n w r)
$$$$
V_{i, t}^{T}+V_{i, t}^{D} \geq V_{i}^{E C \min } \quad i=1, \cdots,(n r+n w r)
$$$$
0 \leq V_{i, t} \leq V_{i}^{\max } \quad i=1, \cdots, n r
$$$$
0 \leq V_{i, t}^{T} \leq V_{i}^{T \max } \quad i=1, \cdots, n r
$$$$
0 \leq V_{i, t}^{D} \leq 99 \quad i=1, \cdots, n r
$$$$
0 \leq h_{i, t} \leq h_{i}^{\max } \quad i=1, \cdots, n r
$$$$
t=1, \cdots, T
$$

where the variables indicate the following: $P_{i, t}$, the active power injection to the grid of hydro plant $i$ at hour $t ; V_{i, t}$, the useful volume stored in the reservoir of the hydro plant $i$ in the period $t ; V_{i-1, t}$, the affluence into reservoir $i$ at period $t$, coming through the river from upstream plant (or plants); $V_{i, t}^{T}$, the turbined volume at hour $t$ by plant $i$; $V_{i, t}^{D}$, the deviated (spilled) volume at hour $t$ by plant $i$; $V_{i, t}^{C}$, the output water consumption for social uses delivered by plant $i$ at hour $t$; and $h_{i, t}$, the height of reservoir $i$ at hour $t$. The following are the parameters in the optimisation formulation: $c_{t}$, the expected market price of hour $t ; V_{i, t}^{A F}$, the individual affluence into reservoir $i$ at period $t$, not considering the flows coming through the 
river from the previous plant; $t_{V}$, the TTW between the considered HPPs; $V_{i, 1}^{S P}$ and $V_{i, T}^{S P}$, the specified volumes at the beginning and at the end of the horizon (respectively) by plant $i ; \eta_{i}$, the average efficiency of the hydro plant $i$; $g$, the acceleration of gravity; $k_{0, i}, k_{1, i}, k_{2, i}$ and $k_{3, i}$, the coefficients relating volume and height at reservoir $i$; $V_{i}^{U}$, the unused volume for electricity generation of reservoir $i$; $V_{i}^{C T \min }$, the minimum daily requirements of water for social uses in hydro plant $i ; V_{i}^{C \min }$ and $V_{i}^{C \max }$, the minimum and maximum (respectively) hourly requirements of water for social uses, in plant $i ; V_{i}^{E C \max }$, the minimum (ecological) volume to be maintained in the river downstream of reservoir $i ; V_{i}^{\max }$ and $V_{i}^{T \max }$, the maximum useful reserve and capacity of production (respectively) of hydro plant $i$; and $h_{i}^{\max }$, the maximum height at plant $i$. In the equations, $n r$ is the number of hydro plants with reservoirs, $n w r$ is the number of fluent hydro plants (without reservoir), $\alpha i$ is the set of hydro plants upstream from the reservoir $i$ and $T$ is the number of discretisation steps.

The goal of the optimisation problem (1)-(15) is to calculate the optimal production of coordinated hydro plants in a basin in $\mathrm{T}$ periods and considering the expected prices in the market (1). Equality constraints (2) and (3) express the energy balances in the hydro plants with and without a reservoir, respectively. When the hydro plant has storage capacity (2), the useful volume in the reservoir can be increased by the individual affluence (rain, tributaries, etc.) and the flows coming from the immediately upstream hydro plants. Additionally, the energy stored in these plants can be reduced by electricity generation and social consumption. When large inflows enter the reservoir, a portion of the water can be deviated by using the spill way to preserve the security of the plant's operation. The amounts of useful energy at the reservoirs at the beginning and end of the programming horizon (5), (6) are pre-specified quantities. The hydro production efficiency for power production is expressed by using a third-order polynomial Equations (7), (8), as a function of the height. In hydro reservoirs with large nonlinear relationships between the height and the stored water (Equation (7)), partial approximations by using third order polynomial equations for each level of the reservoir can be adopted. In the present formulation, the social requirements for water are represented as minimum daily consumptions (9) and restrictions on hourly water flows (10). The operation of the hydrological system requires maintaining the minimum ecological levels of water flows into the basin (11). In Equations (12)-(15), the maximum capacities of the equipment of the hydro plants are expressed.

In the present analysis, the algorithm is solved by using Matlab [30]. Equations (1)-(15) constitute a large nonlinear optimisation problem requiring $(T(7 n r+$
$6 n w r))$ variables, $(4 T(n r+n w r)+2 n r)$ equality restrictions and $(T(16 n r+14 n w r))$ inequality constraints.

\section{The Test Case}

The proposed optimisation problem (1)-(15) is applied to water management in the upper basin of the Guadalquivir River, Spain. Figure 2 shows a map of the headwaters of the Guadalquivir River.

Figure 3 shows a schematic representation of four hydro power plants (HPPs). Three of them have a reservoir (HPP 1, Doña Aldonza; HPP 3, Guadalmena; and HPP 4, Marmolejo), and the other (HPP 2, Pedro Marín) is runof-the-river. The TTW between the plants is shown in the diagram as $T_{v}$. Other important data related to the plants are presented in Tables 3, 4 of the Appendix.

In the present analysis, typical prices in the Daily Market in March 2011 (a month with medium hydro production) in Spain are used to simulate the optimal operation of the hydro system (Figure 4). The acceleration of gravity, $g$, is $9.81 \mathrm{~m} / \mathrm{s}^{2}$.

To analyse the effect of the constraints on electricity production, several cases are considered:

- Case A: base case, in which social consumptions and ecological flows are not represented. Therefore, the optimisation problem is solved without considering Equations (9)-(11).

- Case B: ecological flows are not considered. The optimisation problem is solved without Equation (11). In this case, the social consumptions are included in the formulation.

- Case C: social consumptions are not applied. The optimisation problem is solved without Equations (9) and (10). In this case, the ecological flows are included in the formulation.

- Case D: solution of the optimisation problem (1)-(15), considering both social consumptions and ecological flows.

In all of the cases, the same flow $\left(7.944 \mathrm{Hm}^{3} /\right.$ day, the average flow of March 2011) is considered. The same flow $\left(3.972 \mathrm{Hm}^{3} /\right.$ day in each HPP) is injected at the heads of the basin and uniformly distributed over 24 hours $\left(0.1655 \mathrm{Hm}^{3} /\right.$ hour in each HPP). For simplicity in the analysis, no individual affluences $\left(V_{i, t}^{A F}\right)$ in HPPs 2 and 4 are considered.

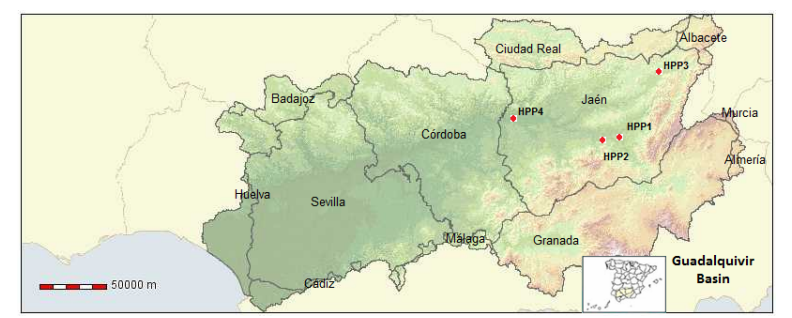

Figure 2. Geographical position of the Guadalquivir basin and relevant hydro power plants [31]. 


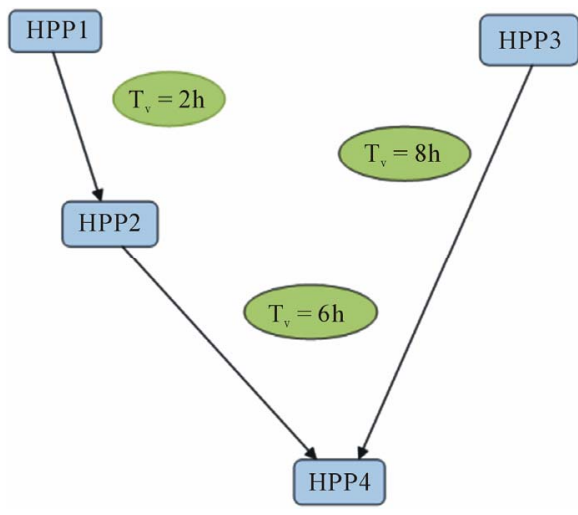

Figure 3. Spatial distribution of the reservoirs in the upper Guadalquivir basin.

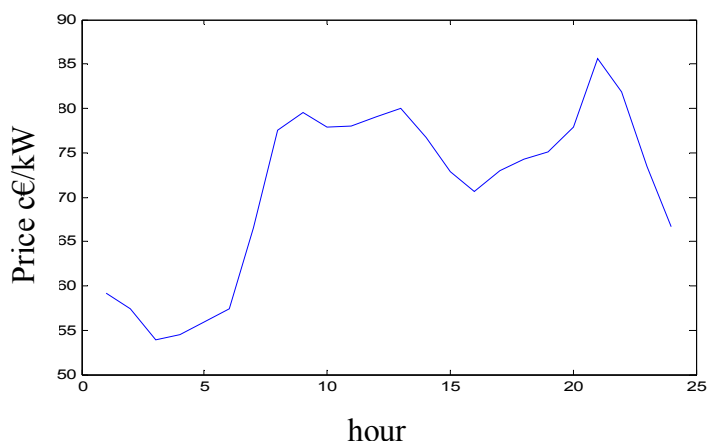

Figure 4. Typical spanish next-day market prices in march 2011.

For this sample basin, assuming 24 hours of operation and hourly discretisation, the formulation described by (1)-(15) implies 648 variables, 390 inequality constraints and 1488 inequality restrictions.

\section{Results}

\subsection{Base Case, without Social Consumption and Ecological Flows}

In Figure 5, the optimal production of the four hydro plants is shown. The hydro plants at the head of basin (HPPs 1 and 3) put the resources into circulation, if possible, during the high-price periods in the morning. However, the behaviour of these two plants is quite different due to the TTW between the plants in the basin and the type of plants downstream. The production of HPP 1 is limited by the capacity of the run-of-the-river HPP 2 located downstream. In this scheme, all of the water entering HPP 2 is turbined, obtaining the maximum possible profit in the combined operation. HPP3, with a controllable power plant downstream (HPP 4), generates electricity during the early hours of the day at the highest prices and full capacity. The resources coming from HPP 2 and HPP 3 reach HPP 4 in time to be turbined at full power during the hours of maximum daily price. A small quantity of water is turbined by HPP 3 at the hour of the maximum price of the day, hour 21, without reaching HPP 4 during the daily horizon.

As shown in Figure 6, hydro plants HPP 1 and HPP 3 (at the heads of the basin) use the water stored at the beginning of the day to increase production during the first hours. The inflows in the heads in the evening help recover the specified final values of stored energy at the end of the day. As expected, HPP 2 has no storage capacity. HPP 4 utilises its storage capabilities to wait for higher prices to sell its production in the market.

The reduced storage capacity of HPP 2 distributes the profits throughout the entire programming period (Figure 7). A higher generation capacity in the plants would centralise the revenue only at the peaks of the price curve. The profit of the joint operation is 165.6 M€.

\subsection{Optimal Operation Considering only Social Consumption}

In this case, the effect of social consumption is studied. Social-consumption values are required in all of the plants. The daily minimum consumption and the hourly limit at each plant are specified in Table 3 of the Appendix, fifth and twelfth columns, respectively.

Figure 8 shows that at the beginning of the day HPP 1 turbines more than the maximum generation capacity of HPP 2, delivering water for social consumption to HPP 2 and HPP 4. This period has the lowest prices of the day. In the other head plant (HPP 3), social requests are supplied using water with less economic efficiency, eliminating HPP 3 generation at hour 21 (Figure 5). Figure 9 shows the delivery of water for social uses for the four hydro plants. The upstream plants, HPPs 1, 2 and 3, transfer the volumes for social consumption at the beginning of the day, the period with lowest prices. HPP 4, without individual inflows, must yield to this restriction along the following minima of the price curve (hours 16 and 24). HPP 3 , with the largest social consumption, also uses the minimum price at hour 24 to fulfil the social requirements. The profile of incremental profits is similar, considering (Figure 10) or without considering (Figure 7) social consumption. However, the final profits are

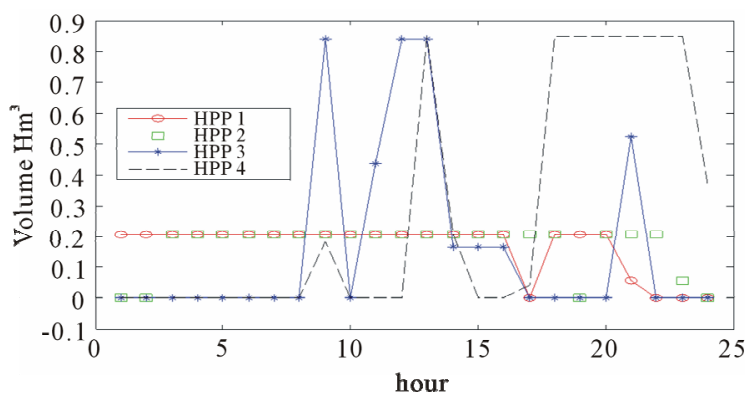

Figure 5. Production in the four hydro plants, Case A. 


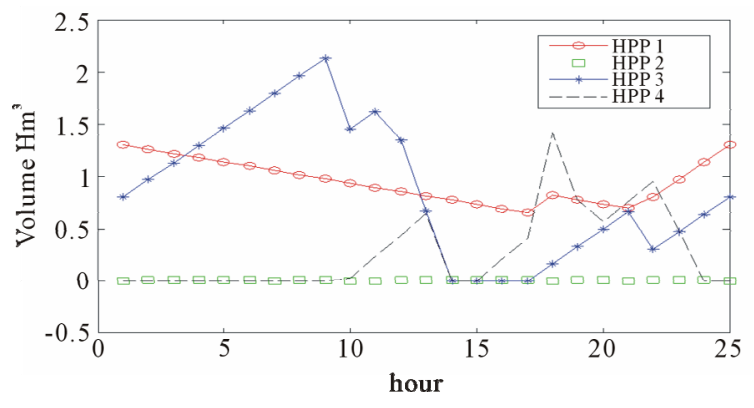

Figure 6. Energy storage in the hydro plants, Case A.

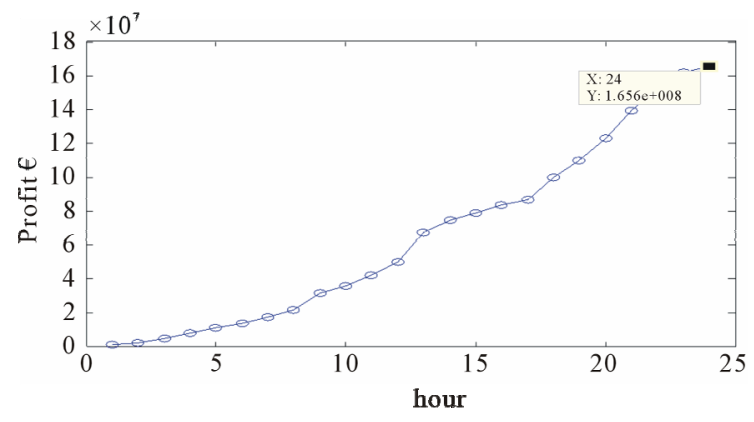

Figure 7. Incremental profits in the basin, Case A.

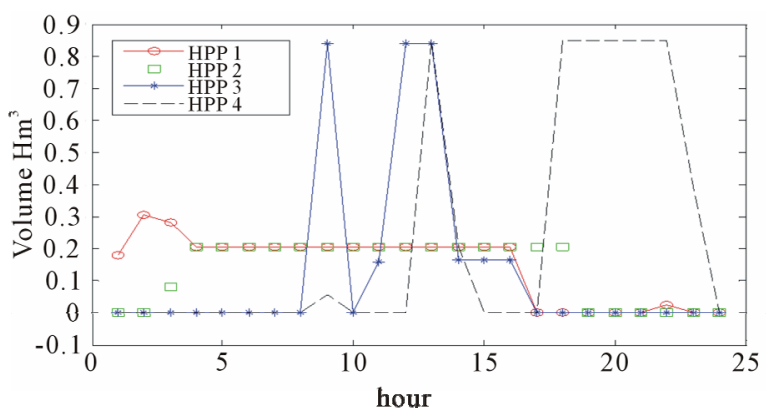

Figure 8. Production in the four hydro plants, Case B.

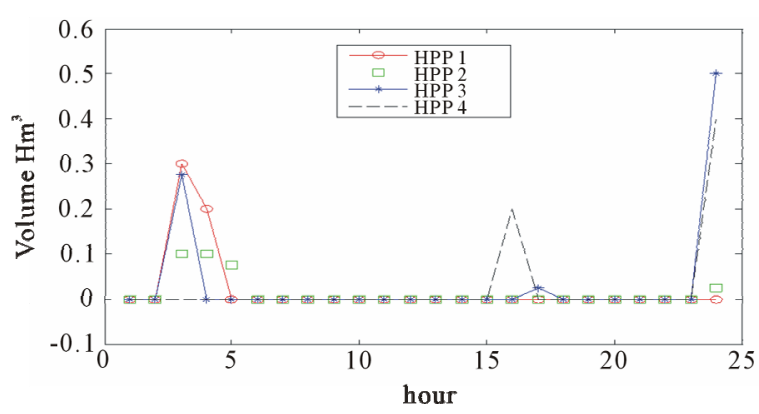

Figure 9. Energy storage in the hydro plants, Case B.

different. When considering social requirements, the total revenue is $137.09 \mathrm{M} €, 17.20 \%$ lower than without human consumption in the basin.

\subsection{Optimal Operation with only Ecological Constraints}

In this case, the individual impacts of the environmental

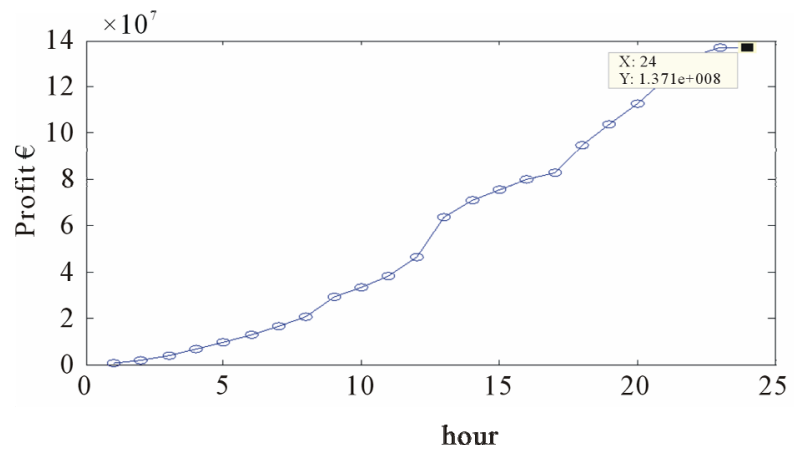

Figure 10. Incremental profits in the basin, Case B.

restrictions (minimum flows in the river) on the profits are analysed. In the present simulations, this restriction can only be imposed at the head plants (HPPs 1 and 3). A constant value of $16 \mathrm{~m}^{3} / \mathrm{s}$ for each plant is considered. With this value, the minimum ecological flows in all of the basins can be maintained [32], considering TTW.

Figure 11 shows that the two head plants (HPPs 1 and 3) generate electricity at all hours of the day. As in Case A, the generation of HPP 1 is restricted by the limited capacity of HPP 2, and HPP 3 mainly generates electricity during the first high-price periods of the day. The ecological restrictions (minimum flow at all hours) make the slope of income almost constant (Figure 12). The profile of the volume turbined becomes flatter, and therefore, there are fewer resources for producing at the hours of maximum price. The optimal profit in this case reaches $163.14 \mathrm{M} €(1.5 \%$ less than that without ecological restrictions). In the present simulations, the restrictions on minimum flows in the river do not significantly reduce the profit of operation. It must be stressed that these restrictions are not consumptive; they only change the generation times of head HPPs 1 and 3. However, theincrease in the amount of ecological flow can reduce the total profits.

\subsection{Optimal Operation with Social Consumption and Ecological Constraints}

In this case, the effects of the two types of constraints (social consumption and minimum flows) are analysed. In this case (Figure 13), the optimal profiles of generation are similar to those observed in Case B (Figure 8). However, some differences must be highlighted. First, the ecological minimum flows require generation at HPPs 1 and 3 during all periods. The distribution of social consumption is also dissimilar (Figure 14). In Case B (with social consumption but without considering ecological restrictions, Figure 9), the volumes for social consumption are assigned to hours 2 to 5 in HPPs 1 and 2 . The ecological flow requirement shifts the delivery of HPP 1 to hours 2 and 7 and the release of HPP 2 to the end of the day (hours 19 to 24). In HPP 3, delivery for 




Figure 11. Production in the hydro plants, Case C.



Figure 12. Incremental profits in the basin, Case $\mathbf{C}$.



Figure 13. Production in the hydro plants, Case D.

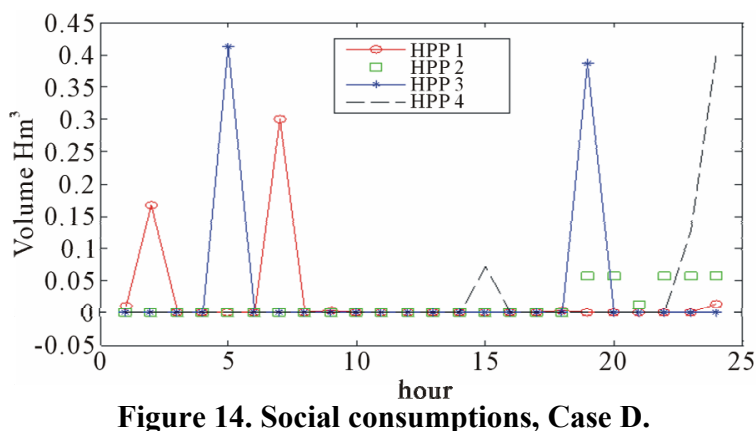

social consumption is increased at hour 19 and eliminated at hour 24. HPP 4 continues to provide for social consumption at the end of the day (hour 24) but shifts to small delivery from hour 16 to 15 . These changes optimise the utilisation resources, increasing the combined profit of the operation. However, the optimal income in this case is $129.90 \mathrm{M} €, 21.54 \%$ less than that of the base case (without social restrictions and ecological constraints).

\subsection{Comparison of the Analysed Cases}

As previously discussed, the economic results of the previous section depend on the type of restrictions added to the base case. Minimum flows in the river can be maintained without a loss of resources, only changing the time of generation. However, the social uses of water are consumptive constraints, extracting resources from the basin. Moreover, the economic results are a function of the amount of available resources. Therefore, three different scenarios are compared here: dry, medium and wet scenarios, for the two types of restrictions. The medium value coincides with the previous affluence (7.94 $\mathrm{Hm}^{3} /$ day). For comparison purposes, all of the results are obtained by maintaining the data previously used, in particular, the price profile shown in Figure 3.

\subsubsection{Results Considering Only Ecological Constraints}

In the present simulations, the ecological requirements of Table $1\left(1.6 \mathrm{~m}^{3} / \mathrm{s}\right.$ in HPPs 1 and 3$)$ are maintained. However, the effect of the ecological constraints is evaluated in three different situations of affluence.

In Table 1, the first column shows the total inflow in the basin injected in head HPPs 1 and 3. The second and third columns show the optimal incomes obtained without considering or including the ecological constraints (Equations (9)-(11)), respectively. The economic difference between the two previous cases is represented in the fourth column. In the fifth column of the table, the relative cost of the ecological constraints, for each $\mathrm{Hm}^{3}$ of inflow in the head HPPs, is calculated. Finally, the sixth column shows the relative cost of the ecological constraints, for each $\mathrm{Hm}^{3}$ of minimum flow requested at the head HPPs of the basin. In this table, it can be seen that the cost of maintaining the ecological constraints depends on the amount of resources injected to the basin. In Figure 15, the curve of variation in the ecological cost (EC) as a function of the affluence is presented.

As shown in Table 2 and Figure 15, the cost of maintaining the ecological requirements is far more important in dry scenarios. In fact, maintaining the same ecological flow of $3.42 \mathrm{Hm}^{3}$ /day is relatively ten times more expensive than maintaining a flow of 12.47 $\mathrm{Hm}^{3} /$ day.

\subsubsection{Results Considering only Social Consumptions}

In the present section, the effect of social consumption (as specified in Table 3, Appendix) in the three previous scenarios of affluence is considered.

Table 2 has the same structure as Table 1 but considers the costs of water delivered for social consumption. 
Table 1. Costs of ecological requirements for different inflows.

\begin{tabular}{cccccc}
\hline $\begin{array}{c}\text { Flow in HPPs 1 and 3 } \\
\left(\mathrm{Hm}^{3} / \mathrm{da}\right)\end{array}$ & $\begin{array}{c}\text { Income, Case A. } \\
(\mathrm{M} €)\end{array}$ & $\begin{array}{c}\text { Income, Case C. } \\
(\mathrm{M} €)\end{array}$ & $\begin{array}{c}\text { Income Gap. } \\
(\mathrm{M} €)\end{array}$ & $\begin{array}{c}\text { Relative Ecological Costs, } \\
\left(€ / \mathrm{Hm}^{3}\right)\end{array}$ & $\begin{array}{c}\text { Relative Ecological Cost, } \\
\left(€ / \mathrm{Hm}^{3}\right)\end{array}$ \\
\hline 12.47 & 228 & 227 & 1.4 & 112,549 & 507,646 \\
7.94 & 166 & 163 & 3 & 305,253 & 877,073 \\
3.42 & 80 & 67 & 13 & $3,801,169$ & $4,947,837$ \\
\hline
\end{tabular}

Table 2. Social consumption costs for different inflows.

\begin{tabular}{cccccc}
\hline $\begin{array}{c}\text { Flow in HPPs 1 and 3 } \\
\left(\mathrm{Hm}^{3} / \mathrm{da}\right)\end{array}$ & $\begin{array}{c}\text { Income, Case } \\
\text { A. }(\mathrm{M} €)\end{array}$ & $\begin{array}{c}\text { Income, Case } \\
\text { B. }(\mathrm{M} €)\end{array}$ & $\begin{array}{c}\text { Income Gap. } \\
(\mathrm{M} €)\end{array}$ & $\begin{array}{c}\text { Relative Social Consumption } \\
\text { Costs, }\left(\mathrm{M}^{\prime} / \mathrm{Hm}^{3}\right)\end{array}$ & $\begin{array}{c}\text { Relative Social Consumption } \\
\text { Cost, }\left(\mathrm{M} € / \mathrm{Hm}^{3}\right)\end{array}$ \\
\hline 12.47 & 228 & 208 & 20 & 2 & 9 \\
7.94 & 166 & 137 & 29 & 4 & 13 \\
3.42 & 80 & 38 & 42 & 12 & 19 \\
\hline
\end{tabular}

According to the two tables, the costs of water allocated for social uses are larger than those of maintaining the ecological constraints. In fact, for the medium scenario, the reduction in profit due to the social uses of water is $967 \%$ greater than the decrease in revenue due to the ecological constraints. Social uses extract resources from the basin; the ecological constraints only request a modi- fication in the profile of generation, but the resource re- mains in the river.

In Figure 16, the relative social consumption costs for the three scenarios of affluence are shown. The curve $S C$, Social Consum., shows the cost of delivering $1 \mathrm{Hm}^{3}$ of water from the basin for social uses in the simulated scenarios. The values of this curve can be used to calculate the price of water allocated for human use in the basin as a function of the profits lost in electricity generation.

\section{Conclusions}

This paper presents an optimisation method to calculate the optimal operation of a basin with both controllable and non-controllable hydro power plants. This program considers both social and ecological restrictions, assessing the economic weight of each of them in the management of resources.

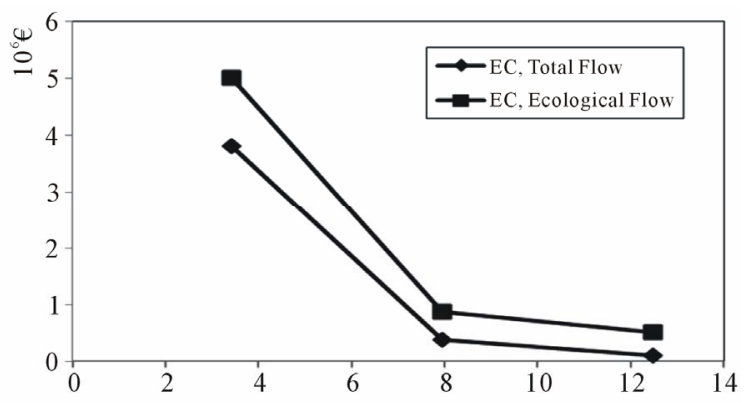

Figure 15. Cost of ecological requirements (EC) for different inflows.

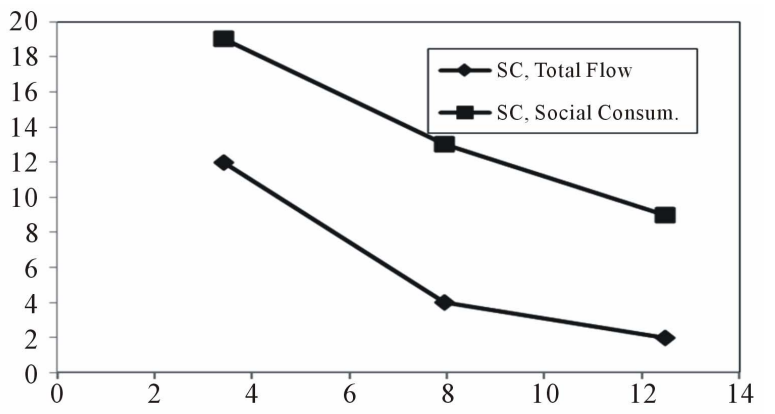

Figure 16. Social consumption (sc) costs for different inflows.

The algorithm allows for control over the actions of fluent HPPs, modifying the operation of controllable HPPs. The method calculates the maximum profit electricity generation in the daily power market, considering ecological constraints and the social use of water.

The study of different inflow states shows that in this case the relative value of the social consumption of water is larger than that of maintaining ecological flows in the basin. Moreover, initial evaluations of the costs of providing water for social uses are performed. The proposed algorithm can be easily extended to consider other operational restrictions on the hydro systems.

\section{Acknowledgements}

The authors would like to acknowledge the Ministry of Science and Technology of Spain (Projects IT2009-0063, ENE2010-16074 and CENIT-CONSOLIDA) for supporting this work.

\section{REFERENCES}

[1] "Concerning Common Rules for the Internal Market in 
Electricity and Repealing Directive 96/92/EC," European Parliament and of the Council, 1996. http://www.cne.es/cne/doc/legislacion/Directiva96_92.pdf

[2] "The Spanish Electric System 2010," Red Eléctrica de España (REE), Madrid, 2011.

[3] R. Sternberg, "Hydropower: Dimensions of Social and Environmental Coexistence," Renewable Sustainable Energy Reviews, Vol. 12, No. 6, 2008, pp. 1588-1621. doi:10.1016/j.rser.2007.01.027

[4] M. Markoff and A. Cullen, "Impact of Climate Change on Pacific Northwest Hydropower," Climate Change, Vol. 87, No. 3/4, 2008, pp. 451-469. doi:10.1007/s10584-007-9306-8

[5] I. P. Holman, D. Tascone and T. M. Hess, "A Comparison of Stochastic and Deterministic Downscaling Methods for Modeling Potential Groundwater Recharge under Climate Change in East Anglia, UK: Implications for Groundwater Resource Management," Hydrogeology Journal, Vol. 17, No. 7, 2009, pp. 1629-1641. doi:10.1007/s10040-009-0457-8

[6] M. Marie, B. François, K. Stéphane and L. Robert, "Adaptation to Climate Change in the Management of a Canadian Water-Resources System Exploited for Hydropower," Water Resources Management, Vol. 23, No. 14, 2009, pp. 2965-2986.

[7] S. Soares and A. A. F. M. Carneiro, "Optimal Operation of Reservoirs for Electric Generation," IEEE Transactions on Power Delivery, Vol. 6, No. 3, 1991, pp. 1101-1107. doi:10.1109/61.85854

[8] S. Granville, G. C. Oliveira, L. M. Thome, N. Campodonico, M. L. Latorre, M. V. F. Pereira and L. A. Barroso, "Stochastic Optimization of Transmission Constrained and Large Scale Hydrothermal Systems in a Competitive Framework," Proceedings of the Power Engineering Society General Meeting, 2003.

[9] C. Cheng, S. Liao, Z. Tang and M. Zhao, "Comparison of Particle Swarm Optimization and Dynamic Programming for Large Scale Hydro Unit Load Dispatch," Energy Conversion and Management, Vol. 50, No. 12, 2009, pp. 30073014. doi:10.1016/j.enconman.2009.07.020

[10] G. C. Oliveira, S. Binato and M. V. F. Pereira, "ValueBased Transmission Expansion Planning of Hydrothermal Systems under Uncertainty," IEEE Transactions on Power Systems, Vol. 22, No. 4, 2007, pp. 1429-1435. doi:10.1109/TPWRS.2007.907161

[11] O. B. Fosso, A. Gjelsvik, A. Haugstad, B. Mo and I. Wangensteen, "Generation Scheduling in a Deregulated System. The Norwegian Case," IEEE Transactions on Power Systems, Vol. 14, No. 1, 1999, pp. 75-81. doi:10.1109/59.744487

[12] A. Kanudia and R. Loulou, "Robust Responses to Climate Change via Stochastic MARKAL: The Case of Québec," European Journal of Operational Research, Vol. 106, No. 1, 1998. pp. 15-30. doi:10.1016/S0377-2217(98)00356-7

[13] H. Habibollahzadeh and J. A. Bubenko, "Application of Decomposition Techniques to Short-Term Operation Planning of Hydrothermal Power System," IEEE Transactions on Power Systems, Vol. 1, No. 1, 1986, pp. 41-47.

\section{doi:10.1109/TPWRS.1986.4334842}

[14] E. Castronuovo and J. A. P. Lopes, "Optimal Operation and Hydro Storage Sizing of a Wind-Hydro Power Plant," International Journal of Electrical Power Energy Systems, Vol. 26, No. 10, 2004, pp. 771-778. doi:10.1016/j.ijepes.2004.08.002

[15] G. Zhao and M. Davison, "Optimal Control of Hydroelectric Facility Incorporating Pump Storage," Renewable Energy, Vol. 34, No. 4, 2009, pp. 1064-1077. doi:10.1016/j.renene.2008.07.005

[16] H. M. I. Pousinho, V. M. F. Mendes and J. P. S. Catalão, "Scheduling of a Hydro Producer Considering Head-Dependency, Price Scenarios and Risk-Aversion," Energy Conversion and Management, Vol. 56, 2012, pp. 96-103. doi:10.1016/j.enconman.2011.11.020

[17] D. N. Simopoulos, S. D. Kavatza and C. D. Vournas, "An Enhanced Peak Shaving Method for Short Term Hydrothermal Scheduling," Energy Conversion and Management, Vol. 48, No. 11, 2007, pp. 3018-3024. doi:10.1016/j.enconman.2007.07.001

[18] A. L. Diniz and M. E. P. Maceira, "A Four-Dimensional Model of Hydro Generation for the Short-Term Hydrothermal Dispatch Problem Considering Head and Spillage Effects," IEEE Transactions on Power Systems, Vol. 23, No. 3, 2008, pp. 1298-1308. doi:10.1109/TPWRS.2008.922253

[19] Z. Shawwash, K. Thomas, K. Siu and S. O. D. Russell, "The BC Hydro Short Term Hydro Scheduling Optimization Model," IEEE Transactions on Power Systems, Vol. 15, No. 3, 2000, pp. 1125-1131. doi:10.1109/59.871743

[20] J. I. Pérez-Díaz and J. R. Wilhelmi, “Assessment of the Economic Impact of Environmental Constraints on ShortTerm Hydropower Plant Operation," Energy Policy, Vol. 38, No. 12, 2010, pp. 7960-7970. doi:10.1016/j.enpol.2010.09.020

[21] J. I. Peréz-Díaz, R. Millán, D. García, I. Guisández and J. R. Wilhelmi, "Contribution of Regulation Reservoirs Considering Pumping Capability to Environmentally Friendly Hydropower Operation," Energy, Vol. 48, No. 1, 2011, pp. 144-152.

[22] European Parliament and of the Council, "Establishing a Framework for Community Action in the Field of Water Policy," Directive 2000/60/EC of the European Parliament and of the Council, 2000.

http://www.madrid.org/rlma web/html/web/FichaNormat iva.icm?ID=296

[23] Government of Spain, Ministry of the Presidency, Royal Legislative Decree 1/2001, Water Act, 2001.

http://www.boe.es/boe/dias/2001/07/24/pdfs/A26791-268 17.pdf

[24] Consejeria de Medio Ambiente, Junta de Andalucia, Royal Decree Law 1/2001, 2011.

http://www.juntadeandalucia.es/medioambiente/

[25] CNE, Comisión Nacional de Energía, Royal Decree Law 54/1997, Law of the Electric System. http://www.cne.es/cne/doc/legislacion/NE_LSE.pdf

[26] Government of Spain, Ministry of the Presidency. Royal Decree 661/2007, Establishing the Regulation of the Ac- 
tivity of the Electric Power Production in the Special Regime. http://www.cne.es

[27] J. M. Y. Loyo, “The Electric Demand," 2011.

http://www.unizar.es/jmyusta/wp-content/uploads/2011/0 1/CONTRATACION-SUMINISTRO-ELECTRICO-Ener o-2011.pdf

[28] OMEL-OMIL, "Results of the Iberian Market," 2011. http://www.omel.es/inicio/mercados-y-productos/mercad o-electricidad/diario-e-intradiario/mercado-diario

[29] J. Martínez-Crespo, J. Usola and J. L. Fernández, "Security-Constrained Optimal Generation Scheduling in LargeScale Power Systems," IEEE Transactions on Power Sys- tems, Vol. 21, No. 1, 2006, pp. 321-332. doi:10.1109/TPWRS.2005.860942

[30] MATLAB, "The Languages of Technical Computing," Version 7.10.0.499, Math Works, 2010.

[31] Government of Spain, Ministry of Environment, "Guadalquivir's Description," 2011.

http://www.chguadalquivir.es/opencms/portalchg/laDema rcacion/guadalquivir/breveDescripcion/

[32] Confederación Hidrográfica del Guadalquivir, "Ecological Flows," 2011.

http:/www.chguadalquivir.es/opencms/portalchg/marcoL egal/planHidrologicoCuenca/ 


\section{Appendix}

Table 3. Hydro plants data.



In Table 3, Prev. HPP is the number of the HPP upstream to the current HPP (i.e., upstream HPP 4 there are the HPP's 2 and 3).

Table 4. Coefficients volume-height of the hydro plants.

\begin{tabular}{ccccc}
\hline HPP & $k_{0}[\mathrm{~m}]$ & $k_{1}\left[\mathrm{~m}^{-2}\right]$ & $k_{2}\left[\mathrm{~m}^{-5}\right]$ & $k_{3}\left[\mathrm{~m}^{-8}\right]$ \\
\hline 1 & $-3.58 \mathrm{E}+01$ & $4.94 \mathrm{E}+00$ & $-1.07 \mathrm{E}-01$ & $1.02 \mathrm{E}-07$ \\
2 & 25 & 0 & 0 & 0 \\
3 & $2.53 \mathrm{E}+00$ & $4.75 \mathrm{E}-01$ & $-6.85 \mathrm{E}-04$ & $1.03 \mathrm{E}-07$ \\
4 & $9.63 \mathrm{E}-01$ & $3.71 \mathrm{E}-01$ & $-3.90 \mathrm{E}-04$ & $1.05 \mathrm{E}-07$ \\
\hline
\end{tabular}




\section{Biographies}

Gloria Hermida was born in Coruña (1973), received her B.S degree in Industrial Engineering from University of La Coruña (2007) and her Master degree in Electrical, Electronics and Automation Engineering (2011) from University Carlos III de Madrid. She is working as Assistant Professor in the Department of Electrical Engineering of University Carlos III de Madrid. Her research interests include the optimization of water resources and operation planning.

Edgardo D. Castronuovo received a B.S. degree (1995) in Electrical Engineering from the National Uni- versity of La Plata, Argentina; both M.Sc. (1997) and Ph.D. (2001) degrees from the Federal University of Santa Catarina, Brazil, and performed Post-Doctorate (2005) at INESC-Porto, Portugal. He worked at the Power System areas of CEPEL, Brazil, and INESC-Porto, Portugal. Currently, Dr. Castronuovo is an Associate Professor at the Department of Electrical Engineering, University Carlos III of Madrid, Spain. His interests are in optimization methods applied to power system problems, renewable production, storage and deregulation of the electrical energy systems. Prof. Castronuovo is Senior Member of IEEE. 